\title{
Evaluation of the Accumulation Status of Microcystin; LR in Rice (Oryza sativa) Grains
}

\author{
Wijewickrama M.M., Manage M. M* \\ Centre for Water Quality \& Algae Research, Department of Zoology, \\ University of Sri Jayewardenepura, Sri Lanka. \\ *pathmalal@sjp.ac.lk
}

\begin{abstract}
Irrigation with Microcystin-LR (MC-LR) contaminated water poses a potential to accumulate MC-LR in plant tissues.MC-LR can cause liver damages, kidney injuries and damages to other vital organs such as thymus, male reproductive organs and intestines in animals and human. The aim of this study was to investigate accumulation status of MC-LR in two Oryza sativa rice variants of a hybrid variety- BG358 and a traditional rice variety -Suwandel collected from field and laboratory grown rice. Paddy plants were exposed to fresh blooms of the genera Microcystis sp. in the laboratory study and samples of $O$. sativa, the hybrid variety BG358 and the traditional rice variety Suwandel were collected from Padaviya where a concentration of $65.11 \pm 0.63 \mu \mathrm{g} / \mathrm{l}$ (diluted) MC-LR in irrigation water has been detected. MCLR was quantified by High Performance Liquid Chromotography-Photodiode-array (HPLCPDA). The mean concentration of MC-LR in O. sativa, variants BG358 and Suwandel of the laboratory study was $567.52 \pm 4.88 \mu \mathrm{g} / \mathrm{kg}$ and $429.83 \pm 4.39$, and for the field samples was $20.97 \pm 0.31 \mu \mathrm{g} / \mathrm{kg}, 18.19 \pm 0.16 \mu \mathrm{g} / \mathrm{kg}$, respectively. The evaluated mean human health risk due to intake of MC-LR via O. sativa, variants BG358 and Suwandel in the laboratory study was $2.84 \pm 0.01 \mu \mathrm{g} / \mathrm{kg}$ and $0.22 \pm 0.01 \mu \mathrm{g} / \mathrm{kg}$ of body weight per day and for the field samples of $O$. sativa, variants BG358 and Suwandel was $0.10 \pm 0.01 \mu \mathrm{g} / \mathrm{kg}$ and $0.009 \pm 0.01 \mu \mathrm{g} / \mathrm{kg}$ of body weight per day, respectively. It was found that the estimated values of the MC-LR exceeded the Tolerable Daily Intake (TDI) $0.04 \mu \mathrm{g} / \mathrm{kg}$ of body weight per day. The mean bioaccumulation factor (BAF) for the laboratory samples of $O$. sativa, variants BG358 and Suwandel was $0.17 \pm 0.03$ and $0.11 \pm 0.01$, respectively. In the field study, the mean BAF for $O$. sativa, variants BG358 and Suwandel was $0.11 \pm 0.01$ and $0.10 \pm 0.01$, respectively. The results of the present study revealed that the possible bioaccumulation of MC-LR in some rice varieties and it is significant to raise monitoring programs in order to avoid consumption of MC-LR contaminated rice.
\end{abstract}

Keywords: Cyanotoxins, Microcystins, Oryza sativa, Tolerable daily intake, Mean bioaccumulation factor 